3

4

22 *Corresponding author: email: tkaranf@clemson.edu; phone: +1-864-656-1005; fax: +1-864-656-0672
Mahmut S. Ersan, David A. Ladner, Tanju Karanfil*

Department of Environmental Engineering and Earth Sciences

Clemson University, Anderson, SC 29625, USA
Submitted to Water Research

May 18, 2016

(1)

\section{The Control of N-Nitrosodimethylamine, Halonitromethane, and Trihalomethane Precursors by Nanofiltration}




\section{ABSTRACT}

24 Nanofiltration (NF) is a promising technology for removing precursors of disinfection byproducts

25 (DBPs) from source waters prior to oxidant addition in water treatment. The aims of this study 26 were to investigate (i) the removal efficiencies of N-nitrosodimethylamine (NDMA), 27 halonitromethane (HNM), and trihalomethane (THM) precursors by NF membranes from different 28 source water types (i.e. surface water, wastewater impacted surface water, and municipal and 29 industrial wastewater treatment effluents), (ii) the impact of membrane type, and (iii) the effects 30 of background water components (i.e., $\mathrm{pH}$, ionic strength, and $\mathrm{Ca}^{2+}$ ) on the removal of selected 31 DBP precursors from different source waters. The results showed the overall precursor removal 32 efficiencies were 57-83\%, 48-87\%, and 72-97\% for NDMA, HNM, and THM precursors, 33 respectively. The removal of NDMA precursors decreased with the increases in average molecular 34 weight cut off and negative surface charge of NF membranes tested, while the removal of THM 35 precursors was slightly affected. $\mathrm{pH}$ changes increased the removal of NDMA precursors, but $\mathrm{pH}$ 36 did not affect the removal of THM and HNM precursors in municipal WWTP effluent. On the

37 other hand, $\mathrm{pH}$ changes had little or no effect on DBP removal from industrial WWTP effluent. In 38 addition, regardless of the membrane type or background water type/characteristics, ionic strength 39 did not show any impact on DBP precursor removals. Lastly, an increase in $\mathrm{Ca}^{2+}$ concentration 40 enhanced the removal of NDMA precursors while a slight decrease and no effect was observed for 41 THM and HNM precursors, respectively, in municipal WWTP effluent.

42 Keywords: DBP Precursors, NDMA, HNM, THM, Nanofiltration, Water Chemistry 


\section{INTRODUCTION}

46 Disinfection is a required process in drinking water treatment worldwide to eliminate

47 pathogenic microorganisms. However, an unintended consequence is the formation of disinfection

48 by-products (DBPs) due to the reaction between precursors and oxidants. Owing to various health

49 effects posed by DBPs, the US Environmental Protection Agency (USEPA) has been imposing

50 increasingly stringent regulations for DBPs under the Disinfectants/DBP Rule (D/DBPR)

51 (USEPA, 2013). The Stage 2 D/DBPR requires water utilities to comply with maximum

52 contaminant levels for $\mathrm{TTHM}_{4}$ (bromodichloromethane [BDCM], bromoform [CHBr3],

53 chloroform $\left[\mathrm{CHCl}_{3}\right]$, dibromochloromethane [DBCM]) and $\mathrm{HAA}_{5}$ (dibromoacetic acid [DBAA],

54 dichloroacetic acid [DCAA], monobromoacetic acid [MBAA], monochloroacetic acid [MCAA],

55 trichloroacetic acid [TCAA]) at $80 \mu \mathrm{g} / \mathrm{L}$ and $60 \mu \mathrm{g} / \mathrm{L}$, respectively, as a locational running annual

56 average in distribution systems. As a result, water utilities have in some cases switched to

57 alternative disinfectants (e.g., chloramine, chlorine dioxide, and ozone) to reduce the formation of

58 THMs and HAAs, which are the major DBPs of chlorination. Nevertheless, other unregulated

59 DBPs such as N-nitrosodimethylamine (NDMA) and halonitromethanes (HNMs) have been

60 observed during chloramination and ozonation-chlorination, respectively (Chen and Valentine,

61 2006; Krasner et al., 2006; Mitch et al., 2003; Nawrocki and Andrzejewski, 2011; Selbes et al.,

62 2014, 2013; Song et al., 2010). NDMA is reported as a potential human carcinogen and has been

63 detected mainly in distribution systems during chloramination of finished waters (Russell et al.,

64 2012). Due to health concerns associated with NDMA, the California Department of Health

65 Services set an NDMA action level of $10 \mathrm{ng} / \mathrm{L}$ (CDPH, 2010). USEPA has been considering

66 NDMA for regulation during the six year review of the D/DBPR. It has also been reported that 
67 HNMs are one of the most cytotoxic and genotoxic classes among the emerging DBPs, having

orders of magnitude higher toxicity than the regulated THMs and HAAs (Plewa et al., 2004).

One of the approaches to control the formation of DBPs during water treatment is to eliminate their precursors before oxidant addition. Various treatment techniques including enhanced coagulation, powdered and granular activated carbon adsorption, ion exchange, nanofiltration (NF) and reverse osmosis have been studied for this purpose (Beita-Sandí et al., 2016; Boyer and Singer, 2005; Gan et al., 2013; Krauss et al., 2010; Miyashita et al., 2009; Schmidt and Brauch, 2008; Snyder et al., 2007; Uyak et al., 2007). Although the removal efficiency of NDMA precursors (e.g. DMA, MEA, DEA, DPA, DMS, ranitidine, DMAE, DMAP, Michler’s ketone, DMHA, and gramine) by NF membranes has been evaluated for selected model precursors (Krauss et al., 2010; Miyashita et al., 2009; Schmidt and Brauch, 2008), there is very limited information about their NF removal from natural source waters with different water characteristics (Snyder et al., 2007; Woods et al., 2016). Natural organic matter (NOM) is known as one of the main precursor of THMs, which is generally associated with higher molecular weight organic molecules as opposed to NDMA precursors (Gerecke and Sedlak, 2003; Krasner et al., 2013; Mitch and Sedlak, 2004), which are mostly related to small molecular weight compounds (Gerecke and Sedlak, 2003; Krasner et al., 2009; Mitch and Sedlak, 2004; Pehlivanoglu-Mantas and Sedlak, 2008; Selbes et al., 2013). Several studies have examined the removal of NOM from laboratory simulated and natural waters by NF (Braghetta et al., 1997; Cho et al., 1999; Hong and Elimelech, 1997; Schafer et al., 1998). These studies have shown that the change in solution characteristics had an impact on size and structure of molecules as well as the conformation of the membrane surface (Ghosh and Schnitzer, 1980). Even though several studies have examined the removal of THM precursors 
by NF due to regulatory concerns, there is a lack of information regarding the removal of unregulated DBP precursors (e.g., NDMA, HNMs) by NF membranes.

The objective of this study was to examine the removal of selected unregulated (i.e., NDMA and HNMs) and regulated THM precursors by NF membranes under varying background water chemistry conditions. The removal of these precursors from two municipal wastewater treatment plant effluents, one industrial wastewater effluent, one wastewater impacted surface water, and one non-impacted surface source were evaluated. Experiments were conducted at different pH (69), ionic strength (0.005-0.05 M), $\mathrm{Ca}^{2+}$ concentration (6 - $\left.60 \mathrm{mg} / \mathrm{L}\right)$, and with different $\mathrm{NF}$ membranes to assess the effectiveness of NF filtration on DBP precursor control. To the best of our knowledge, this is the first study in literature providing a side-by-side comparison of NDMA, HNM, and THM precursor removals under various water chemistry conditions. The results provide insights about the control of emerging and regulated DBP precursors using NF membranes.

\section{MATERIALS AND METHODS}

\subsection{Filtration Experiments}

Three commercially available flat sheet polyamide thin film composite NF membranes, TS80, ESNA 1-LF2 and NF270 (TriSep Corp., Hydranautics, and FilmTec Corp., respectively) were tested (Table 1). In each experiment, membranes were initially cleaned following a procedure described elsewhere (Ersan et al., 2015) to prevent the leaching of NDMA precursors from membranes. In brief, membranes were flushed with $\sim 5 \mathrm{~L}$ of $1 \mathrm{mg} / \mathrm{L}$ chlorine solution. Afterwards, the feed tank solution was replaced with distilled and de-ionized (DDI) water and membranes were flushed until no residual chlorine remained in the permeate side. All experiments were carried out at $25 \pm 1^{\circ} \mathrm{C}$ and at a pressure of 34.5 bar (500 psi) using a cross-flow filtration cell (Fig. S1). The 
113 effective area of the membrane cell was $140 \mathrm{~cm}^{2}$. Treated water samples were collected in $500 \mathrm{~mL}$ 114 amber glass bottles from the permeate side of the membrane and tested for desired analytes.

115 The removal efficiency, $R(\%)$ was calculated as

$$
R=\left(1-\frac{C_{p}}{C_{f}}\right) * 100
$$

117 where $C_{p}$ is the concentration in the permeate and $C_{f}$ is the concentration in the feed.

118 During filtration experiments, flux data were also obtained and normalized according to 119 Equation 2 to account for flux changes with changing background water characteristics and coupon 120 to coupon variability.

$$
J_{N}=\left(\frac{J_{f}}{J_{c w}}\right)
$$

122 Here $J_{N}$ is the normalized flux, $J_{f}$ is the final flux at the end of the experiment, and $J_{c w}$ is the clean123 water flux, measured using DDI water.

\section{2.2. Experimental Design}

In this study three sets of experiments were systematically conducted to evaluate the effect of 126 different variables on the removal of DBP precursors. The first experimental set was to determine 127 the effect of source water type on NDMA, HNM and THM precursor removal using one membrane 128 (TS80). There were five different source waters (Table 2): a non-impacted surface water (SW) that 129 serves as a source for a drinking water treatment plant, a wastewater impacted surface water (ISW), 130 treated effluents of two municipal wastewater treatment plants (WWTP-1, WWTP-2), and an 131 industrial (textile dying/finishing) wastewater treatment plant (IWWTP) effluent. Water samples 132 were immediately filtered with pre-washed $0.2 \mu \mathrm{m}$ cartridge filters (Whatman ${ }^{\mathrm{TM}}$ Polycap $^{\mathrm{TM}} \mathrm{TC}$ ) 133 upon arrival at the laboratory to eliminate biological activity and were stored for no longer than 10 134 days at $4^{\circ} \mathrm{C}$ in the dark. 
The second experimental set was to evaluate the effect of membrane type on the removal of

136 NDMA and THM precursors. Table S1 shows the experimental matrix. One water source

137 (municipal WWTP effluent) was used and three membranes were evaluated: TS80, NF270, and 138 ESNA.

139 The third experimental set was to evaluate the effects of $\mathrm{pH}$, ionic strength, and $\mathrm{Ca}^{2+}$ 140 concentration on DBP precursor removal. One membrane type was used along with two source 141 waters: municipal and industrial WWTP effluents. Using factorial design, eight different 142 experiments were performed per water type. Tables S2 and S3 show the experimental matrices 143 (one for each water type). Feed solutions were adjusted to the target $\mathrm{pH}$ values by addition of $\mathrm{HCl}$ 144 or $\mathrm{NaOH} . \mathrm{Ca}^{2+}$ and ionic strengths of the feed solutions were adjusted sequentially to keep the 145 target ionic strength concentrations the same for the waters under analogous experimental 146 conditions. While the target $\mathrm{Ca}^{2+}$ levels were adjusted with $\mathrm{CaCl}_{2}$ addition, the ionic strengths of 147 the samples were adjusted by addition of $\mathrm{NaCl}$, and the concentration was expressed in molar units 148 as $\mathrm{NaCl}$ (Fisher Scientific, Pittsburgh, PA).

\subsection{NDMA, HNM, and THM Formation Potential Tests}

150 DBP formation potential (FP) tests were conducted under excess amount of oxidant to 151 ensure the highest formation of DBPs. Chloramination, ozonation followed by chlorination, and 152 chlorination were used to determine NDMA, HNM and THM precursors, respectively. For NDMA 153 formation potential (FP) tests, a chloramine stock solution (2500 mg/L as $\mathrm{Cl}_{2}$ ) was prepared by 154 titrating ammonium sulfate stock solution (5000 mg/L) with sodium hypochlorite solution (5000 $155 \mathrm{mg} / \mathrm{L}$ ) at a $\mathrm{Cl}_{2}: \mathrm{N}$ mass ratio of $4: 1$ at $\mathrm{pH}$ 7.8. NDMA FP tests were performed by treating permeate 156 samples with $100 \mathrm{mg} / \mathrm{L}$ chloramine as $\mathrm{Cl}_{2}$ at $\mathrm{pH} 7.8$ in the presence of $20 \mathrm{mM}$ phosphate buffer 157 for 5 days of contact time. 
For HNM FP tests, ozone was generated with a bench scale ozone generator (Model GTC-

1B, Griffin Technics, NJ) fed with ultra-high purity oxygen gas and bubbled with fine diffusers for $50 \mathrm{~min}$ to obtain a stock solution at $25-30 \mathrm{mg} \mathrm{O} / \mathrm{L}$. The concentration of ozone stock solution was measured with a Hach DR/890 colorimeter. Ozone stock solutions were introduced to the water samples at an $\mathrm{O}_{3}$ : DOC mass ratio of $1: 1$ at $\mathrm{pH} 7.8$ in the presence of $20 \mathrm{mM}$ phosphate buffer for $5 \mathrm{~min}$. Chlorine stock solutions $\left(6250 \mathrm{mg} / \mathrm{L}\right.$ as $\left.\mathrm{Cl}_{2}\right)$ were prepared by diluting sodium hypochlorite stock (5\% available free chlorine), and was spiked into the ozonated samples with a target dose of $50 \mathrm{mg} \mathrm{Cl} / \mathrm{L}$ for $24 \mathrm{~h}$.

For THM FP tests, samples were treated with only chlorine $(50 \mathrm{mg} / \mathrm{L})$ at $\mathrm{pH} 7.8$ for five days. Formation potential tests were conducted for each sample with two measurements. The bars in the data plots represent the mean values, and the error bars show the data range.

\subsection{Statistical Analysis}

To optimize the time required for experiments and to decrease the storage time for water samples, the experiments were conducted using an unreplicated $2^{3}$ factorial treatment structure with the factors: $\mathrm{Ca}^{2+}$ (6 or $\left.60 \mathrm{mg} / \mathrm{L}\right), \mathrm{pH}(6$ or 9$)$ and ionic strength $(0.005 \mathrm{M}$ or $0.05 \mathrm{M})$. The selections of the levels for the factors were made based on characteristics of typical surface and wastewater impacted water sources. Because the experiments were unreplicated, there were no degrees of freedom for estimating experimental error. To obtain a surrogate estimation of the experimental error, the mean squares for two- and three-factor interactions were combined. This approach provides a conservative procedure in that p-values computed using this approach can be larger than the true p-value and may reject the null hypothesis less often than it should be rejected (Oehlert, 2003). If the null hypothesis is rejected, there is an indication of a significant effect due to the factor. Statistical analysis was performed using SAS 9.3 software. 


\subsection{Analytical methods}

182 All analytical methods are described in the supporting information section (S1) and summarized 183 in Table S4. They were also reported in our previous publications (Beita-Sandí et al., 2016; Gan 184 et al., 2013; Selbes et al., 2013; Uzun et al., 2015).

\section{RESULTS AND DISCUSSION}

\subsection{Characteristics of Water Sources}

In the examined waters, DOC, SUVA254 and ionic strength ranged between 2.2 - $26 \mathrm{mg} / \mathrm{L}, 0.9$ 189 - 4.6 L/mg.m, and $8 \times 10^{-4}-1 \times 10^{-2} \mathrm{M}$ (as $\mathrm{NaCl}$ ), respectively. The two municipal wastewater effluents had distinctly higher DON and ionic strength levels as compared to other waters. $\mathrm{pH}$ 191 values of all the waters were between 7.2 - 8.0. The DBP FPs of the samples ranged from 112 1921078 ng/L for NDMA, 7 - 46 g/L for HNM, and 230 - $1092 \mu \mathrm{g} / \mathrm{L}$ for THM (Table 2). In general, 193 municipal wastewater effluents had higher NDMA and HNM formation potentials as compared to 194 non-impacted and impacted surface water sources. This may be attributed to the abundance of 195 reactive NDMA and HNM precursors in wastewater sources. THM FP values varied and it was 196 highest in the industrial effluent. In general, THM levels correlated well with the DOC 197 concentrations ( 90\%).

While municipal WWTP-1 effluent samples were collected at three different times (Table 2, 3 199 and 4), industrial WWTP effluent samples were collected twice for different sets of experiments

200 (Table 2 and 4). The observed levels of DBPs in municipal WWTP-1 ranged between 544 - 1078 201 ng/L, 139 - $308 \mu \mathrm{g} / \mathrm{L}, \mathrm{ND}$ - $27 \mu \mathrm{g} / \mathrm{L}$, while in IWWTP they were between 71 - 193 ng/L, 695 -

$2021092 \mu \mathrm{g} / \mathrm{L}$, and 16 - $52 \mu \mathrm{g} / \mathrm{L}$ for NDMA, THM, and HNM, respectively. These variations in water 203 qualities suggests that not only the availability but also the reactivity of precursors in source waters 
may change based on the time of sample collection, which in turn results in variability in formation potential of DBPs.

\subsection{Removal of NDMA, HNM and THM Precursors}

The removal efficiencies of the TS80 NF membrane for NDMA, HNM, and THM precursors are shown in Fig. 1; they were 57-83\%, 48-87\%, and 72-97\%, respectively. In general, the removal of THM precursors was higher than those of NDMA and HNM precursors. This was attributed to the higher molecular weight of THM precursors (i.e., NOM) than NDMA precursors, which has been linked to small molecular weight compounds of anthropogenic origin (Gerecke and Sedlak, 2003; Krasner et al., 2013; Mitch and Sedlak, 2004). The focus of this analysis is on size exclusion as the main mechanism responsible for differences in transport among precursor types; however, it is recognized that other factors such as physicochemical characteristics of the precursors (i.e., hydrophilicity, hydrophobicity, charge, etc.) might also affect the overall removal process. Ascertaining the chemical structure and properties of precursors in a more detailed way is beyond the scope of this work, but is an interesting endeavor that should be pursued. More developments in structure and property knowledge will enable a better understanding of the mechanisms at play in membrane transport of DBP precursors.

Focusing on the NDMA data in Fig. 1, precursor removals from different sources varied according to the following sequence: WWTP-2 $>$ WWTP-1 $>$ ISW $>$ SW $>$ IWWTP. Higher NDMA precursor removals were observed for the effluents of two municipal wastewater treatment plants (WWTP-2 and WWTP-1) and for the impacted surface water (ISW) than for the nonimpacted surface water (SW) and industrial wastewater effluent (IWWTP). This suggests that municipal wastewater effluents and impacted surface waters tested in this study either contained relatively larger precursors or some particle-associated NDMA precursors (Mitch and Sedlak, 
227 2004). The lower NDMA precursor removal observed for the industrial wastewater effluent and 228 the non-impacted surface water was attributed to the presence of small molecular sized NDMA 229 precursors. These results suggest that NDMA precursors originating from different sources can be 230 different in terms of their molecular sizes (or perhaps other properties), which in turn affects their 231 rejection by NF membranes.

232 Focusing on the HNM data in Fig. 1, precursor removals varied according to the following 233 sequence WWTP-2 > IWWTP $>$ ISW $>$ SW $>$ WWTP-1. It is notable that in one case the HNM 234 precursor removal was much lower than NDMA precursor removal, while in the other cases HNM 235 precursors were removed similarly to or higher than NDMA precursors. This finding indicates that 236 the size and/or chemical characteristics of HNM precursors varied from source to source, and the 237 size and types of HNM precursors were different than those of NDMA.

238 Focusing on the THM data in Fig.1, the precursor removal sequence was as follows: IWWTP $239>$ WWTP-2 > ISW > WWTP-1 > SW. In all studied water sources, the removal of THM precursors 240 by the NF membrane was higher than NDMA or HNM precursors. This suggests that THM 241 precursors are relatively large as compared to NDMA and HNM precursors. The largest THM 242 precursors were apparently in the industrial wastewater (IWWTP), with the impacted source water 243 (ISW) and one of the municipal wastewater effluents (WWTP-2) also having fairly large THM 244 precursors. The other municipal wastewater effluent (WWTP-1) and the non-impacted surface 245 water (SW) apparently had smaller THM precursors. Previous studies have shown that the removal 246 of THM precursors by NF membranes ranged between 41-98\% (Ángeles et al., 2008; Chellam, 247 2000; Golea et al., 2016; Lin et al., 2006); which is comparable with the values observed in this 248 study.

249 Most of the data presented here are comparisons between feed and permeate precursor 
250 formation potentials. It would also be useful to measure the precursors directly rather than relying 251 on formation potential tests alone. The molecular structure of the precursors is not known, so direct 252 measurements are not possible, but we were able to measure bulk DOC and DON in an effort to 253 draw correlations. Overall the removal of DOC and DON from the studied source waters ranged 254 between 77 to $97 \%$ and 37 to $80 \%$, respectively (Fig. S2). When percent removal of DBPs were 255 plotted as a function of DOC removal (Fig. S3), there was a good correlation between THMFP 256 and DOC removal $\left(r^{2}=0.90\right)$ (Fig. S3-a), which suggest that percent DOC removals can be used 257 as a surrogate parameter for THM precursor removals. On the other hand, a much weaker 258 correlation $\left(r^{2}=0.46\right)$ was observed for HNM precursor removals (Fig. S3-b) while no correlation 259 was seen for NDMA precursor removal (Fig. S3-c). As far as correlations between DBP and DON 260 removals, a negative correlation was obtained for THM $\left(\mathrm{r}^{2}=0.40\right)$ and $\operatorname{HNM}\left(\mathrm{r}^{2}=0.66\right)$ precursor 261 removals while no correlation was observed for NDMA precursor removals. The lack of observed 262 correlations suggests that most of the NDMA and HNM precursors are diverse and different than 263 THM precursors.

On the other hand, we also looked at the ratios of DBPFP/DOC in both treated and raw waters 265 to see the possible changes in the reactivity of precursors on the permeate and feed sides of the 266 membrane. Here we are using the term "reactivity" to describe the degree to which precursors are 267 converted to DBPs upon oxidation; a higher reactivity means a higher yield of DBPs. In this sense, 268 DBPFP/DOC ratios in raw water were plotted as a function of DBPFP/DOC ratios in treated waters 269 (Fig. S4), where the solid line (1:1) in the graph indicates that DBPFP/DOC remains the same after 270 NF membrane treatment. If the reactivity of precursors is higher after the treatment, we would 271 expect the data points to be higher than the solid line (1:1) or vice versa. In figure S4-a, the squares 272 falling under the line (for IWWTP and WWTP-2) suggest that the reactivity of THM precursors 
273 were lower in the permeate NF membrane in these waters while opposite was observed for ISW 274 and SW. As for HNM precursors (Fig. S4-b), reactivity of precursors per DOC was higher in the 275 permeate as opposed to raw water.

\section{3.3. The Effect of Membrane Type on the Removal of NDMA and THM Precursors}

277 The effect of membrane type on NDMA and THM precursor removals at different pH (6-9) and 278 ionic strength $(0.005$ - $0.05 \mathrm{M})$ conditions from a municipal WWTP effluent was investigated 279 using three different commercially available NF membranes (TS80, NF270, and ESNA) (Table 280 S3). The results showed that while the removal efficiencies for NDMA precursors were within the 281 range of 78-82\%, 51-58\%, and 57-62\%, for TS80, NF270 and ESNA, respectively, the removals

282 of THM precursors were 83-87\%, 72-80\%, and 87-91\% for TS80, NF270 and ESNA, respectively 283 (Fig. 2).

For the membranes studied, the removal of NDMA precursors decreased with the increasing 285 average molecular weight cut off and negative surface charge (Table 1), which was attributed to 286 the low molecular weight nature of NDMA precursors, while the removal of THM precursors (i.e., 287 NOM) was only slightly affected by the membrane characteristics. Statistical analysis of the results 288 also revealed that the membrane type is an important factor that significantly affects the removal 289 of NDMA and THM precursors (p-values $=0.0001$ and 0.0004 ). As far as water chemistry effects, 290 while the $\mathrm{pH}$ and ionic strength had a significant effect on the removal of NDMA (p-value = 291 0.006), the effect of $\mathrm{pH}$ and ionic strength on THM precursor removal was insignificant (p-value $292=0.0829$ and 0.2929) (Fig. 2).

293 3.4. Effect of Background Water Components on the Removal of NDMA, HNM, and THM 294 Precursors 
As discussed above, differences in precursor characteristics as well as membrane type were contributing factors to the differences in removal efficiencies by NF observed in Fig. 1 and Fig. 2.

297 However, some of these effects could also be attributed to the characteristics of the water matrix,

298 such as $\mathrm{pH}$, ionic strength, and calcium content. A detailed evaluation of these parameters was 299 performed using the factorial experimental design, with the data shown in Fig. 3. The observed 300 removal efficiencies for municipal WWTP effluent (Fig. 3A) ranged between 69 -79\% for NDMA, $30140-64 \%$ for HNM, and 87-93\% for THM precursors. The removal of DBP precursors from the 302 industrial WWTP effluent (Fig. 3B) ranged from 52-66\% for NDMA, 92-96\% for HNM, and 94303 98\% for THM precursors. Observations regarding $\mathrm{pH}$, ionic strength, and calcium are described 304 separately below.

$305 \quad 3.4 .1$ The effect of $\mathbf{p H}$

Investigation of eight different water background conditions showed that, for the tested 307 municipal wastewater effluent, increasing the $\mathrm{pH}$ from 6 to 9 increased NDMA precursor removal. 308 This is shown by comparing the $\mathrm{pH} 6$ and pH 9 bars in Fig. 3A. Statistical analysis reveals that the $309 \mathrm{pH}$ effect was significant, having a p-value of 0.0036. For HNM and THM precursor removals in 310 the municipal wastewater effluent, there were no significant effects of $\mathrm{pH}$ (p-value $=0.8114$ and 311 p-value $=0.2245$.

312 As for industrial wastewater effluent, increasing the $\mathrm{pH}$ from 6 to 9 did not show any 313 significant effect on NDMA, HNM, or THM precursor removals (p-values = 0.0973, 0.6326, 314 0.3692, respectively) (Fig. 3B).

315 Two mechanisms, or a combination of them, are proposed to explain the observed variations 316 in DBP precursor removal with changing background conditions: i) electrostatic charge repulsion 317 based on the acidity constants (pKa) of DBP precursors in different sources and ii) size exclusion. 
318 For instance, NDMA precursors must have been altered such that their charge repulsion was

319 reduced and/or their molecular size was reduced at $\mathrm{pH} 6$ compared to $\mathrm{pH}$ 9. On the contrary, THM

320 precursor removals were not affected by $\mathrm{pH}$ changes in both municipal and industrial WWTP

321 effluent. This suggests that the controlling mechanism for THM precursor removal was size

322 exclusion rather than charge repulsion. $\mathrm{pH}$ is an important factor that affects the size of ionizable

323 THM precursors (i.e. NOM) and also affects the membrane matrix. More specifically, at $\mathrm{pH}$ 9,

324 ionizable macromolecules will be in a linear form due to charge repulsion, while at $\mathrm{pH} 6$, the

325 molecules will be in more compact and spherocolloidal form due to reduced charge repulsion. At

326 the same time, the membrane will be in a more expanded form at $\mathrm{pH} 9$ as opposed to $\mathrm{pH} 6$

327 (Braghetta et al., 1997). Previous studies have found that THM precursors are mostly large

328 molecules and their removal increased with increasing pH (Ángeles et al., 2008; Chellam, 2000;

329 Lin et al., 2006). However, in this study, the results suggest that the removal of THM precursors

330 was mainly controlled by size exclusion. Thus, no $\mathrm{pH}$ effect was observed for both wastewater 331 effluents tested.

As for HNM precursors, although their removal patterns were different in both municipal

333 and industrial WWTP effluents ( 55\% vs 95\%), the change in pH from 6 to 9 was not significant

334 This could also suggest that the molecular structure of HNM precursors was not altered 335 significantly by the change in $\mathrm{pH}$ to affect their removal by the NF membrane.

\subsubsection{The effect of ionic strength}

The effects of ionic strength on the removal of NDMA, HNM, and THM precursors from

338 municipal and industrial WWTP effluent sources are shown in Fig. 3A and B, respectively. In both

339 water types and under all studied conditions, the flux and osmotic pressure have been altered by

340 an increase in ionic strength from $0.005 \mathrm{M}$ to $0.05 \mathrm{M}$, which influences the ion transport across 
341 the NF membrane pores (Park et al., 2010). The flux data suggest that the membrane matrix was

342 in a more expanded state at high $\mathrm{pH}$ or low ionic strength and a less expanded state at low $\mathrm{pH}$ or

343 high ionic strength conditions with respect to intra-membrane electrostatic repulsion forces

344 (Braghetta et al., 1997; Hong and Elimelech, 1997) (Fig. S5-S6). Although there were changes in

345 membrane matrix and precursor charge density, the removal of NDMA, HNM, and THM

346 precursors were not affected by an increase in ionic strength in both examined waters. Statistical

347 analysis of results from the municipal and industrial WWTP effluents also shows that the effect of

348 ionic strength on the removal of DBPs is insignificant $(0.05<\mathrm{p}$-values $)$.

\section{3.4.3. The effects of calcium}

350

351

352
The effect of $\mathrm{Ca}^{2+}$ on the removal of NDMA, HNM, and THM precursors was studied in municipal and industrial WWTP effluent under eight different background conditions and results are shown in Fig. 3A and B. It is plausible that the presence of $\mathrm{Ca}^{2+}$ ions in source waters may influence the removal of DBP precursors by either changing the precursor stability in the water or altering the flux of the membrane filters (Kabsch-Korbutowicz et al., 1999). Under all studied conditions for industrial WWTP effluent, the results indicated that increasing the $\mathrm{Ca}^{2+}$ concentration did not show any significant change on the removal of NDMA, HNM, and THM precursors (p-values $=0.1686,0.2258$, and 0.1709, respectively) (Fig. 3B). However, for municipal WWTP effluent, while the removal of HNM precursors was not significantly affected by a change in background $\mathrm{Ca}^{2+}$ concentration ( $\mathrm{p}$-values $\left.=0.2059\right)$, the removal of NDMA was increased and the removal of THM precursors was decreased. When the $\mathrm{Ca}^{2+}$ content of source waters were increased, a severe flux decline was observed due to formation and/or accumulation of $\mathrm{Ca}^{2+}$-NOM complexes onto the NF membrane surface (Fig. S3-S4). Therefore, the abundance of positively charged divalent ions on the membrane surface might act as a barrier for the small- 
364 sized NDMA precursors thus favoring their rejection by NF membranes. Statistical analysis of 365 examined conditions for municipal WWTP effluent also suggested that an increase in $\mathrm{Ca}^{2+}$ 366 concentration had a significant effect on the removal of NDMA and THM precursors ( $\mathrm{p}$-value = $367 \quad 0.0013$ and $\mathrm{p}$-value $=0.0346)$.

\section{Conclusions}

In this study, the removal of NDMA, HNM, and THM precursors from different types of 371 water/background matrices were investigated using different NF membranes. A cumulative 372 summary of important findings is as follows:

- $\quad$ Based on the characteristics of the NF membranes used, the removal of NDMA precursors decreased with the increases in average molecular weight cut off and negative surface charge, while the removal of THM precursors (i.e., NOM) was slightly affected by the membrane characteristics.

- Among the studied waters, THM precursor removals were always higher than those of NDMA and HNM precursors. The overall precursor removal efficiencies ranged between 57-83\%, 48-87\%, and 72-97\% for NDMA, HNM, and THM precursors, respectively.

- The variation in background $\mathrm{Ca}^{2+}, \mathrm{pH}$ and ionic strength concentrations not only leads to a change in membrane conformation (i.e., surface charge, pore size) but also affects the physicochemical properties of precursors (i.e., charge and size). However, these changes were specific to the membrane type and/or water type.

- The removal of NDMA precursors under varying $\mathrm{Ca}^{2+}$ and $\mathrm{pH}$ conditions were shown to be different from two sources; increase in background $\mathrm{Ca}^{2+}$ and $\mathrm{pH}$ increased the removal 
of NDMA precursors from municipal wastewater effluent, while little or no effect was observed in industrial wastewater effluent.

- Regardless of the background water characteristics and membrane type, change in ionic strength did not show any impact on the removal of all the studied DBPs.

- Although there were differences in the removal efficiencies under varying background water characteristics, which affected flux levels, the variability of removal efficiencies remained within $\sim 10-15 \%$. This suggests relatively stable performance of NF membranes under varying background conditions.

\section{ACKNOWLEDGMENT}

This work was supported, in part, by a research grant from the National Science Foundation (CBET 1236070). Authors would like to acknowledge Dr. James Rieck for his assistance in 397 statistical analysis of the data. 


\section{References}

Ángeles, de la R., Rodríguez, M., León, V.M., Prats, D., 2008. Removal of natural organic matter and THM formation potential by ultra- and nanofiltration of surface water. Water Res. 42, 714-722. doi:10.1016/j.watres.2007.07.049

Beita-Sandí, W., Ersan, M.S., Uzun, H., Karanfil, T., 2016. Removal of N-nitrosodimethylamine precursors with powdered activated carbon adsorption. Water Res. 88, 711-718. doi:10.1016/j.watres.2015.10.062

Boyer, T.H., Singer, P.C., 2005. Bench-scale testing of a magnetic ion exchange resin for removal of disinfection by-product precursors. Water Res. 39, 1265-1276. doi:10.1016/j.watres.2005.01.002

Braghetta, A., Digiano, F.A., Ball, W.P., 1997. Nanofiltration of Natural Organic Matter: pH and Ionic Strength Effects. J. Environ. Eng. 123, 628-641.

CDPH, C.D. of P.H., 2010. Public Drinking Water Systems. Calif. Dep. Public Heal.

Chellam, S., 2000. Effects of nanofiltration on trihalomethane and haloacetic acid precursors removal and speciation in waters containing low concentrations of bromide ion. Environ. Sci. Technol. 34, 1813-1820. doi:10.1021/es991153t

Chen, Z., Valentine, R.L., 2006. Modeling the Formation of N -Nitrosodimethylamine (NDMA) from the Reaction of Natural Organic Matter (NOM) with Monochloramine $†$. Environ. Sci. Technol. 40, 7290-7297. doi:10.1021/es0605319

Cho, J., Amy, G., Pellegrino, J., 1999. Membrane filtration of natural organic matter: Initial comparison of rejection and flux decline characteristics with ultrafiltration and 
nanofiltration membranes. Water Res. 33, 2517-2526. doi:10.1016/S0043-1354(98)00498-9

429 Ersan, M.S., Ladner, D.A., Karanfil, T., 2015. N -Nitrosodimethylamine (NDMA) Precursors

430 Leach from Nanofiltration Membranes. Environ. Sci. Technol. Lett. 2, 66-69.

$431 \quad$ doi:10.1021/acs.estlett.5b00015

432 Gan, X., Karanfil, T., Kaplan Bekaroglu, S.S., Shan, J., 2013. The control of N-DBP and C-DBP

433 precursors with MIEX ${ }^{\circledR}$. Water Res. 47, 1344-1352. doi:10.1016/j.watres.2012.11.049

434 Gerecke, A.C., Sedlak, D.L., 2003. Precursors of N-mitrosodimethylamine in natural waters.

435 Environ. Sci. Technol. 37, 1331-1336. doi:10.1021/es026070i

436 Ghosh, K., Schnitzer, M., 1980. Macromolecular structure of humic substances. Soil Sci. 129, $437 \quad 266-276$.

438 Golea, D., Sutherland, S., Jarvis, P., Judd, S.J., 2016. Pilot-scale spiral wound membrane 439 assessment for THM precursor rejection from upland waters. Sep. Sci. Technol. 51, 13801388. doi:10.1080/01496395.2016.1162807

441

442

443

444

445

446

447

448

449

Hong, S.K., Elimelech, M., 1997. Chemical and physical aspects of natural organic matter (NOM) fouling of nanofiltration membranes. J. Memb. Sci. 132, 159-181. doi:10.1016/s0376-7388(97)00060-4

Kabsch-Korbutowicz, M., Majewska-Nowak, K., Winnicki, T., 1999. Analysis of membrane fouling in the treatment of water solutions containing humic acids and mineral salts. Desalination 126, 179-185. doi:10.1016/S0011-9164(99)00172-1

Krasner, S.W., Mitch, W.A., McCurry, D.L., Hanigan, D., Westerhoff, P., 2013. Formation, precursors, control, and occurrence of nitrosamines in drinking water: A review. Water Res. 47, 4433-4450. doi:10.1016/j.watres.2013.04.050 
450

451

452

453

454

455

456

457

458

459

460

461

462

463

464

465

466

467

468

469

470

471

Krasner, S.W., Weinberg, H.S., Richardson, S.D., Pastor, S.J., Chinn, R., Sclimenti, M.J., Onstad, G.D., Thruston, A.D., 2006. The Occurrence of a New Generation of Disinfection By-Products S1 S2. Environ. Sci. Technol. 40, 7175-7185.

Krasner, S.W., Westerhoff, P., Chen, B., Rittmann, B.E., Amy, G., 2009. Occurrence of disinfection byproducts in United States wastewater treatment plant effluents. Environ. Sci. Technol. 43, 8320-5. doi:10.1021/es901611m

Krauss, M., Longrée, P., Van Houtte, E., Cauwenberghs, J., Hollender, J., 2010. Assessing the fate of nitrosamine precursors in wastewater treatment by physicochemical fractionation. Environ. Sci. Technol. 44, 7871-7877. doi:10.1021/es101289z

Li, Q., Elimelech, M., 2004. Natural organic matter fouling and chemical cleaning of nanofiltration membranes. 4th World Water Congr. Innov. Drink. Water Treat. 4, 245-251. doi:10.1021/es0354162

Lin, Y.L., Chiang, P.C., Chang, E.E., 2006. Reduction of disinfection by-products precursors by nanofiltration process. J. Hazard. Mater. 137, 324-331. doi:10.1016/j.jhazmat.2006.02.016

Mitch, W. a., Sedlak, D.L., 2004. Characterization and Fate of N -Nitrosodimethylamine Precursors in Municipal Wastewater Treatment Plants. Environ. Sci. Technol. 38, 14451454. doi:10.1021/es035025n

Mitch, W.A., Gerecke, A.C., Sedlak, D.L., 2003. A N-Nitrosodimethylamine (NDMA) precursor analysis for chlorination of water and wastewater. Water Res. 37, 3733-3741. doi:10.1016/S0043-1354(03)00289-6

Miyashita, Y., Park, S.-H., Hyung, H., Huang, C.-H., Kim, J.-H., 2009. Removal of Nitrosamines and Their Precursors by Nanofiltration and Reverse Osmosis Membranes. J. 
473 Nawrocki, J., Andrzejewski, P., 2011. Nitrosamines and water. J. Hazard. Mater. 189, 1-18. doi:10.1016/j.jhazmat.2011.02.005

475

476

477

478

479

480

481

482

483

484

485

486

487

488

489

490

491

492

493

Oehlert, G.W., 2003. A First Course in Design and Analysis of Experiments, The American Statistician. doi:10.1198/tas.2003.s210

Park, N., Cho, J., Hong, S., Lee, S., 2010. Ion transport characteristics in nanofiltration membranes: Measurements and mechanisms. J. Water Supply Res. Technol. - AQUA 59, 179-190. doi:10.2166/aqua.2010.034

Pehlivanoglu-Mantas, E., Sedlak, D.L., 2008. Measurement of dissolved organic nitrogen forms in wastewater effluents: Concentrations, size distribution and NDMA formation potential. Water Res. 42, 3890-3898. doi:10.1016/j.watres.2008.05.017

Plewa, M.J., Wagner, E.D., Jazwierska, P., Richardson, S.D., Chen, P.H., McKague, a B., 2004. Halonitromethane drinking water disinfection byproducts: chemical characterization and mammalian cell cytotoxicity and genotoxicity. Environ. Sci. Technol. 38, 62-68. doi:Doi 10.1021/Es0304771

Russell, C.G., Blute, N.K., Via, S., Wu, X., Chowdhury, Z., 2012. Nationwide assessment of nitrosamine occurrence and trends. J. Am. Water Works Assoc. 104, 57-58. doi:10.5942/jawwa.2012.104.0037

Schafer, A., Fane, A.G., Waite, T.D., 1998. Nanofiltration of natral organic matter: Removal, fouling and the influence of multivalent cations. Desalination 118, 109-122.

Schmidt, C.K., Brauch, H.-J., 2008. N,N -Dimethylsulfamide as Precursor for N Nitrosodimethylamine (NDMA) Formation upon Ozonation and its Fate During Drinking 
495

496

497

498

499

500

501

502

503

504

505

506

507

508

509

510

511

512

513

514

Selbes, M., Kim, D., Ates, N., Karanfil, T., 2013. The roles of tertiary amine structure, background organic matter and chloramine species on NDMA formation. Water Res. 47, 945-953. doi:10.1016/j.watres.2012.11.014

Selbes, M., Kim, D., Karanfil, T., 2014. The effect of pre-oxidation on NDMA formation and the influence of pH. Water Res. 66, 169-179. doi:10.1016/j.watres.2014.08.015

Snyder, S. a., Wert, E.C., Lei, H.D., Westerhoff, P., Yoon, Y., 2007. Removal of EDCs and pharmaceuticals in drinking and reuse treatment processes. Am. Water Work. Assoc. Res. Found. Rep. 331.

Song, H., Addison, J.W., Hu, J., Karanfil, T., 2010. Halonitromethanes formation in wastewater treatment plant effluents. Chemosphere 79, 174-179. doi:10.1016/j.chemosphere.2010.01.001

Uyak, V., Yavuz, S., Toroz, I., Ozaydin, S., Genceli, E.A., 2007. Disinfection by-products precursors removal by enhanced coagulation and PAC adsorption. Desalination 216, 334344. doi:10.1016/j.desal.2006.11.026

Uzun, H., Kim, D., Karanfil, T., 2015. Seasonal and temporal patterns of NDMA formation potentials in surface waters. Water Res. 69, 162-172. doi:10.1016/j.watres.2014.11.017

Woods, G.C., Sadmani, A.H.M.A., Andrews, S.A., Bagley, D.M., Andrews, R.C., 2016. Rejection of pharmaceutically-based N-nitrosodimethylamine precursors using nanofiltration. Water Res. 93, 179-186. doi:10.1016/j.watres.2016.02.002 


\section{Table 1. Membrane Characteristics}

\begin{tabular}{|c|c|c|c|}
\hline Designation & ESNA 1-LF2 & TS80 & NF270 \\
\hline Manufacturer & Hydranautics & Trisep & Dow Filmtech \\
\hline Active Layer Composition ${ }^{\mathrm{a}}$ & Polyamide & Polyamide & Polyamide \\
\hline MWCO (Dalton) ${ }^{\mathrm{a}}$ & 200 & 150 & $200-400$ \\
\hline $\mathrm{NaCl}$ Rejection (\%) ${ }^{\mathrm{a}}$ & 80 & $80-90$ & 99 \\
\hline $\mathrm{pH}$ range $\left(25^{\circ} \mathrm{C}\right)^{\mathrm{a}}$ & $2-10$ & $2-11$ & $2-11$ \\
\hline Typical Flux $\left(\mathrm{L} \cdot \mathrm{m}^{2} \cdot \mathrm{hr}^{-1} \cdot \mathrm{psi}^{-1}\right)^{\mathrm{a}}$ & $21 / 75$ & $34 / 110$ & $72-98$ / 130 \\
\hline Surface Charge (at pH:7) & Negative $^{a}$ & Sligthly Negative $^{a}$ & Highly Negative $^{\mathrm{b}}$ \\
\hline
\end{tabular}

516

517 a Specified by the manufacturer. ${ }^{\mathrm{b}}$ Information obtained from the literature (Li and Elimelech, 518 2004).

519 


\section{Table 2. Water Characteristics of Source Waters}

\begin{tabular}{|c|c|c|c|c|c|}
\hline Parameter & SW & ISW & WWTP-1 & WWTP-2 & IWWTP \\
\hline $\mathrm{UV}_{254 \mathrm{~nm}}$ & 0.06 & 0.30 & 0.13 & 0.11 & 0.24 \\
\hline DOC (mg/L) & 2.2 & 6.5 & 5.3 & 4.5 & 26 \\
\hline $\mathrm{SUVA}_{254}(\mathrm{~L} / \mathrm{mg} / \mathrm{m})$ & 2.63 & 4.55 & 2.45 & 2.4 & 0.91 \\
\hline DON (mg/L) & 0.6 & 0.6 & 4.9 & 9.7 & 0.6 \\
\hline $\mathrm{NH}_{4}^{+}(\mathrm{mg} / \mathrm{L})$ & 0.025 & 0.075 & 4 & 0.025 & 2 \\
\hline $\mathrm{Ca}^{2+}(\mathrm{mg} / \mathrm{L})$ & 5 & 4 & 5 & 20 & 2 \\
\hline $\mathrm{pH}$ & 7.7 & 7.2 & 7.6 & 7.4 & 8 \\
\hline Ionic Strength (Molar as $\mathrm{NaCl}$ ) & $8 \times 10^{-4}$ & $9 \times 10^{-4}$ & $3.1 \times 10^{-3}$ & $1 \times 10^{-2}$ & $4.8 \times 10^{-3}$ \\
\hline NDMAFP (ng/L) & 112 & 148 & 1078 & 629 & 193 \\
\hline HNMFP $(\mu \mathrm{g} / \mathrm{L})$ & 7 & 14 & 27 & 46 & 16 \\
\hline THMFP ( $\mu \mathrm{g} / \mathrm{L})$ & 230 & 578 & 244 & 351 & 1092 \\
\hline
\end{tabular}

520

521 SW: Surface Water; ISW: Impacted Surface Water; WWTP-1: Municipal Wastewater Treatment

522 Plant-1; WWTP-2: Municipal Wastewater Treatment Plant-2; IWWTP: Industrial Wastewater 523 Treatment Plant. 


\section{Table 3. Water Characteristics for pH and Ionic Strength}

Experiments using different NF membranes

\begin{tabular}{lc}
\hline Parameter & WWTP-1 \\
\hline $\mathrm{UV}_{254 \mathrm{~nm}}$ & 0.0966 \\
$\mathrm{DOC}(\mathrm{mg} / \mathrm{L})$ & 4.7 \\
$\mathrm{SUVA}_{254}(\mathrm{~L} / \mathrm{mg} / \mathrm{m})$ & 2.1 \\
$\mathrm{DON}(\mathrm{mg} / \mathrm{L})$ & 3.4 \\
$\mathrm{Ca}^{2+}(\mathrm{mg} / \mathrm{L})$ & 12 \\
${ }^{*} \mathrm{pH}$ & $7.2\left(6^{*}-9^{*}\right)$ \\
$*$ Ionic Strength $(\mathrm{Molar}$ as $\mathrm{NaCl})$ & $0.0032\left(0.005^{*}-0.05^{*}\right)$ \\
NDMA FP $(\mathrm{ng} / \mathrm{L})$ & 544 \\
HNM FP $(\mu \mathrm{g} / \mathrm{L})$ & $\mathrm{ND}$ \\
THM FP $(\mu \mathrm{g} / \mathrm{L})$ & 308 \\
\hline \hline
\end{tabular}

524

525 *Values were adjusted according to desired levels. WWTP-1: Municipal Wastewater Treatment 526 Plant-1. ND: Not Detected

527

528

529

530

531

532

533

534

535

536

537 


\begin{tabular}{|c|c|c|}
\hline Parameter & WWTP-1 & IWWTP \\
\hline $\mathrm{UV}_{254 \mathrm{~nm}}$ & 0.050 & 0.337 \\
\hline DOC (mg/L) & 1.9 & 9.7 \\
\hline $\mathrm{SUVA}_{254}(\mathrm{~L} / \mathrm{mg} / \mathrm{m})$ & 2.6 & 3.5 \\
\hline DON (mg/L) & 2.3 & 1 \\
\hline$* \mathrm{pH}$ & \multicolumn{2}{|c|}{$7.5(6 *-9 *)$} \\
\hline *Ionic Strength (Molar as $\mathrm{NaCl}$ ) & \multicolumn{2}{|c|}{$0.0016(0.005 *-0.05 *)$} \\
\hline${ }^{*} \mathrm{Ca}^{2+}(\mathrm{mg} / \mathrm{L})$ & \multicolumn{2}{|c|}{$6\left(6-60^{*}\right)$} \\
\hline NDMA FP (ng/L) & 576 & 71 \\
\hline HNM FP $(\mu g / L)$ & 12 & 52 \\
\hline THM FP ( $\mu g / L)$ & 139 & 695 \\
\hline
\end{tabular}

538

539 *Values were adjusted according to desired levels. WWTP-1: Municipal Wastewater Treatment 540 Plant-1, IWWTP: Industrial Wastewater Treatment Plant. 


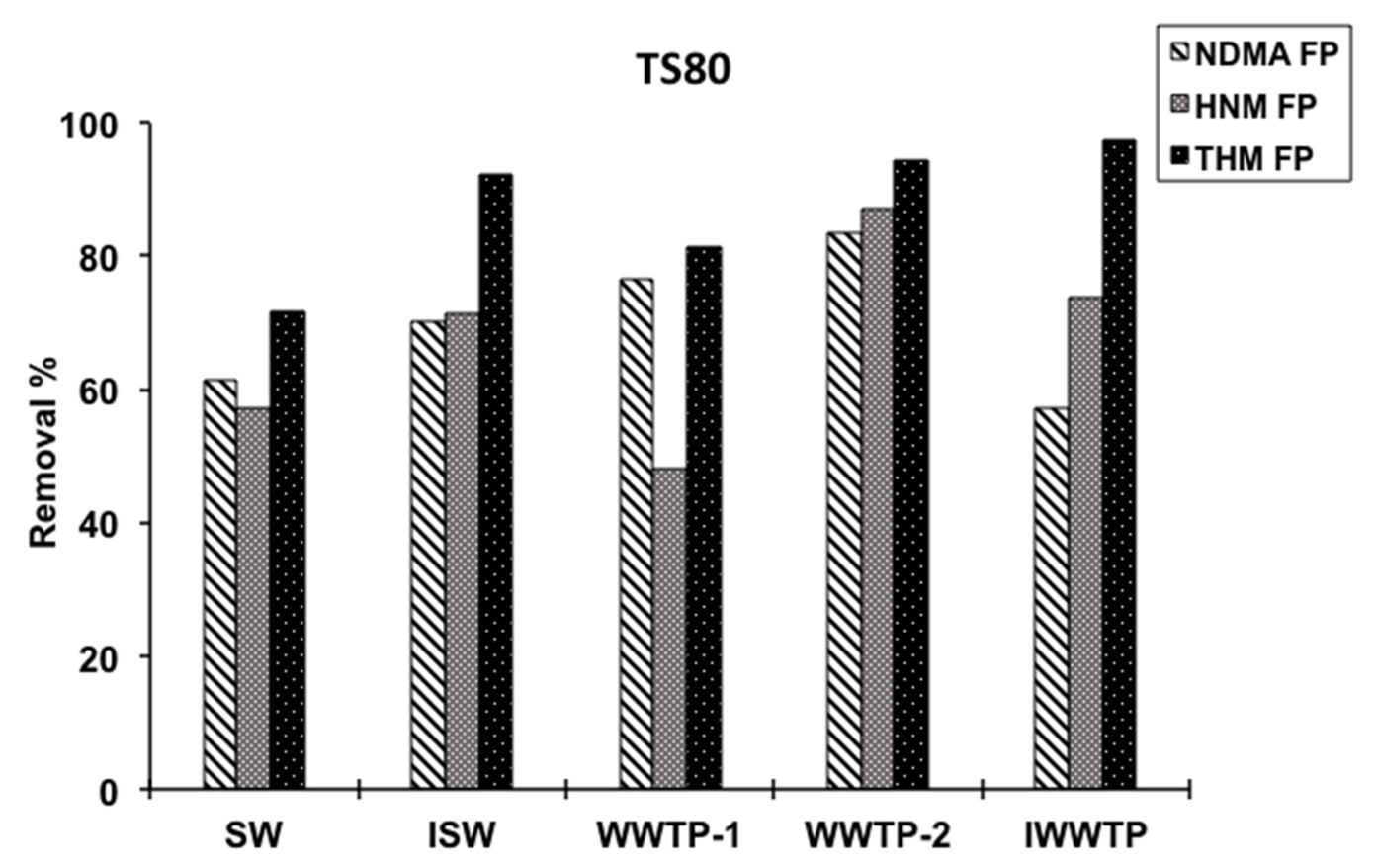

542

543 Figure 1. The removal NDMA, HNM, and THM precursors from different source waters using

544 the TS80 membrane.

545 SW: Surface Water; ISW: Impacted Surface Water; WWTP-1: Municipal Wastewater Treatment 546 Plant-1; WWTP-2: Municipal Wastewater Treatment Plant-2; IWWTP: Industrial Wastewater 547 Treatment Plant.

548

549

550

551

552

553

554

555

556

557

558 

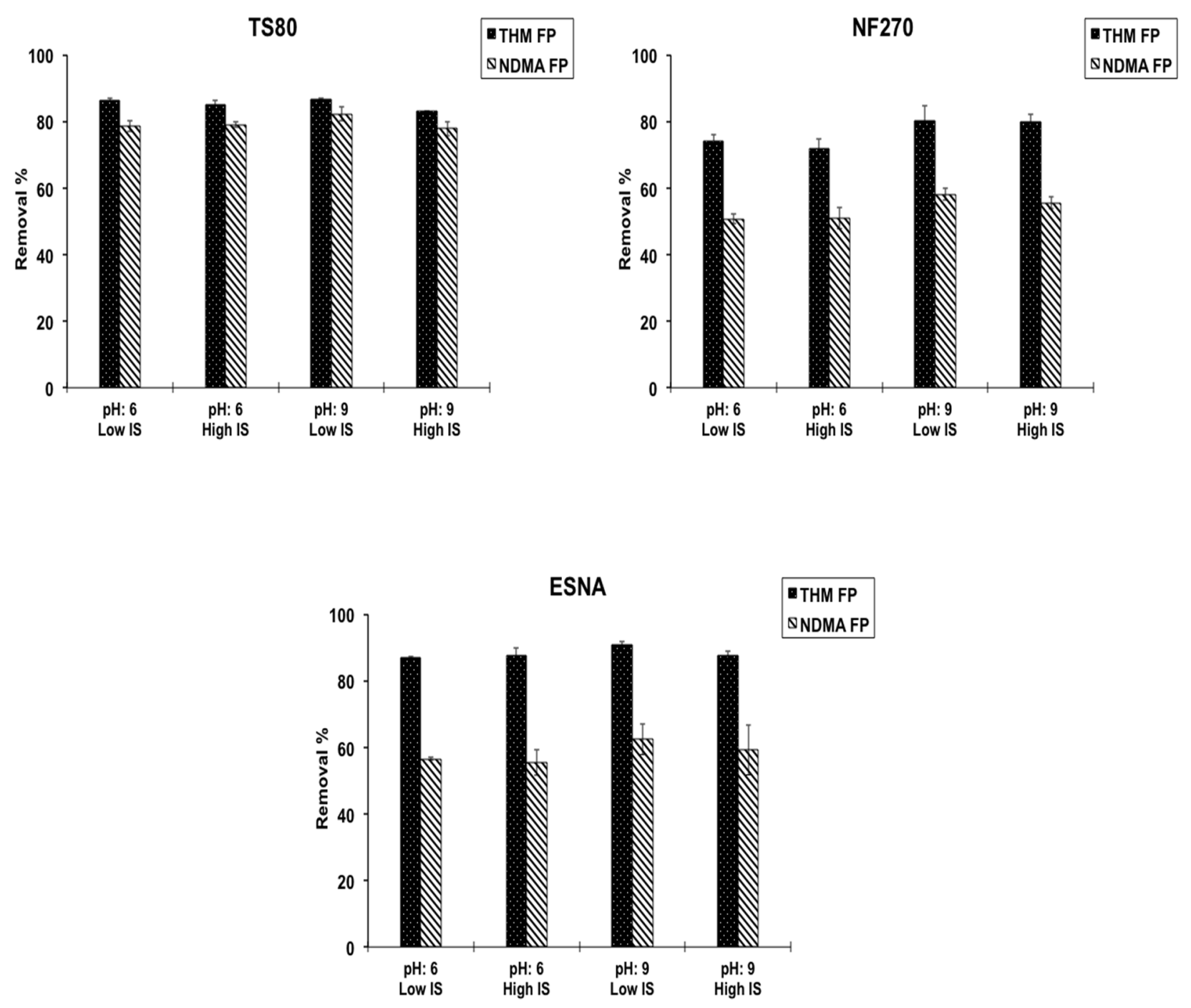

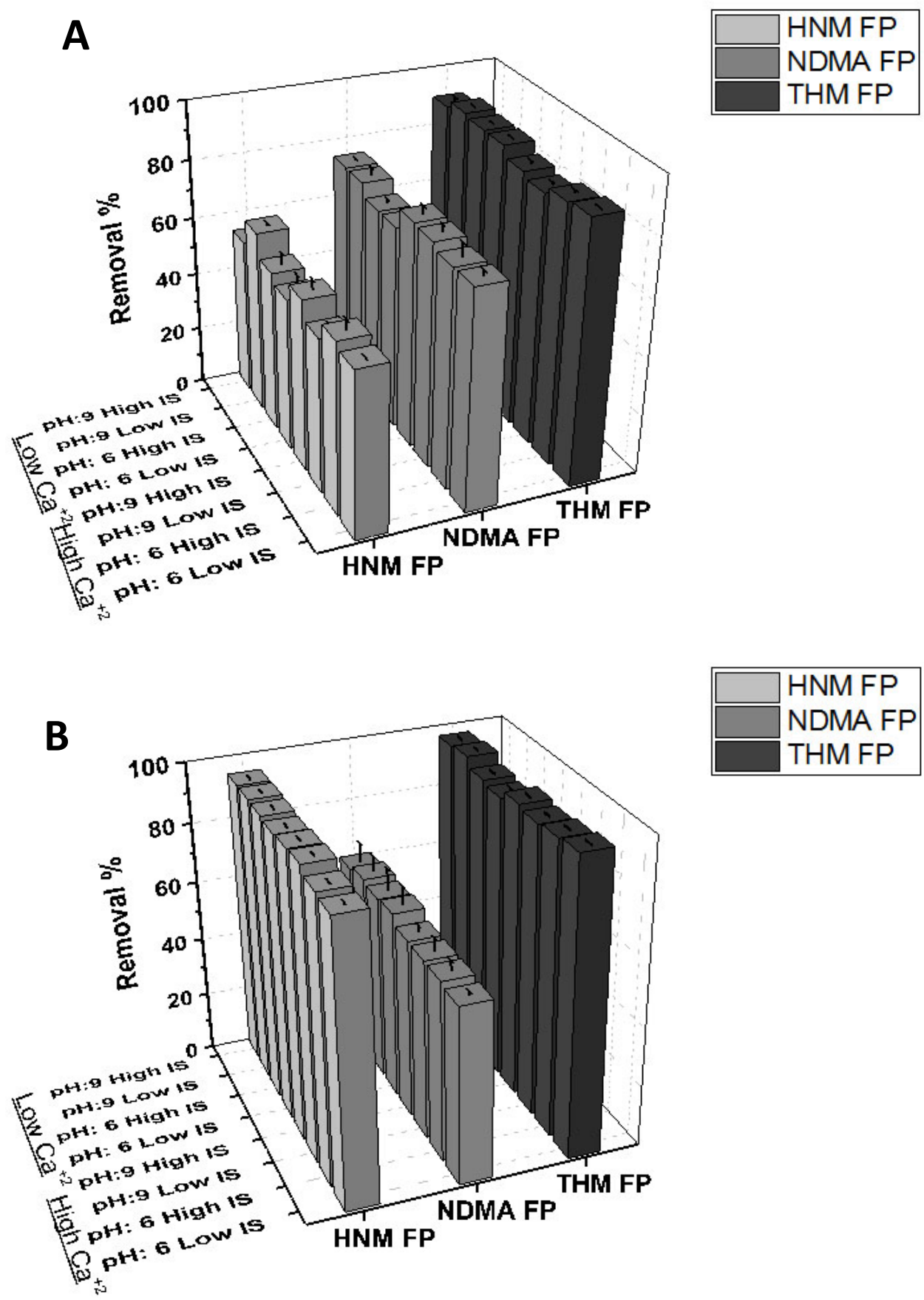

574 Figure 3. Effect of Water Chemistry on the removal of NDMA, HNM, and THM precursors

575 using the TS80 membrane with A) Municipal wastewater effluent (WWTP-1) and B) Industrial

576 wastewater effluent (IWWTP). 